\title{
Intensive Glucose Lowering in Cardiovascular Risk Management
}

- Unsolved Questions -

\author{
Michio Shimabukuro, MD, PhD; Hiroaki Masuzaki, MD, PhD; Masataka Sata, MD, PhD
}

$\mathbf{C}$ ardiovascular disease (CVD) is common and the leading cause of death among people with type 2 diabetes mellitus (DM). A meta-analysis reported that the relative risk for myocardial infarction (MI) and stroke increased by almost $40 \%$ in people with type 2 DM compared with non-diabetics. ${ }^{1}$ It has been shown that the progressive relationship between glucose level and cardiovascular risk extends below the diabetic threshold. ${ }^{2}$ Thus, impaired glucose tolerance (IGT) or postprandial hyperglycemia is as an important determinant for CVD. ${ }^{3}$

\section{Article p 712}

Considerable attention has been focused on determining whether improved glycemic control leads to cardiovascular benefit, ${ }^{4}$ but there is little evidence that intensive treatment of hyperglycemia in type $2 \mathrm{DM}$ patients reduces long-term CVD rates. During the UKPDS trial, there was a $16 \%$ reduction in cardiovascular events (combined fatal or nonfatal MI and sudden death) in the intensive glycemic control arm, although this difference was not statistically significant $(\mathrm{P}=0.052) .{ }^{5}$ After 10 years of follow-up, those originally randomized to intensive glycemic control had modest reductions in MI (15\% with sulfonylurea or insulin, 33\% with metformin) and in all-cause mortality (13 and 27\%, respectively). ${ }^{6}$ However, results of recent large trials (ACCORD: the Action to Control Cardiovascular Risk in Diabetes; ADVANCE: Action in Diabetes and Vascular Disease; VADT: Veterans Affairs Diabetes Trial) indicate that improving glycemic control using $\mathrm{HbA}_{\mathrm{lc}}$ as the marker does not lead to significant improvement in CVD outcomes. ${ }^{7}$ All 3 trials were conducted in participants with longstanding diabetes (mean duration 8-11 years) and either known CVD or multiple cardiovascular risk factors. ${ }^{7}$

There may be at least 3 reasons why the strategy of glucose lowering has failed to achieve CVD risk reduction. (1) A conventional strategy using insulin or sulfonylureas may fail to obtain optimal postprandial glucose levels. Until recently, the predominant focus of therapy has been on lowering the $\mathrm{HbA} 1 \mathrm{c}$ level, with a strong emphasis on fasting plasma glucose. ${ }^{8} \mathrm{How}-$ ever, a growing body of evidence suggests that reducing postprandial plasma glucose excursions is as important or perhaps more important than achieving $\mathrm{HbA}_{1 \mathrm{c}}$ goals. ${ }^{9} \mathrm{HbA}$ cc does not provide a measure of glycemic variability or the postprandial glucose level. (2) Glucose lowering using insulin and/or insulin secretagogues can cause hypoglycemia if the timing of carbohydrate consumption and medication dose are not carefully titrated. Severe hypoglycemia was more likely in participants randomized to the intensive glycemic control arm and might be associated with higher mortality rates. ${ }^{7}$ (3) The glucose lowering strategy would need to be conducted over a much longer period of time, and possibly earlier in the stage of the patient's DM and CVD. ${ }^{6,7,9}$

In this issue of the Journal, Kataoka et al show that glycemic status regardless of the glucose lowering intervention was associated with less progression of coronary atheroma ${ }^{10}$ (Figure). They compared the 1-year effects of lifestyle intervention, voglibose, $\alpha$-glucosidase inhibitor, and nateglinide, a short-acting insulin secretagogue on coronary atherosclerotic changes in patients with coronary artery disease with either IGT or type 2 DM in a prospective randomized open-label multicenter trial. There were no differences in glucose control and coronary atheroma size after 1-year of treatment among three study groups. Interestingly, by post-hoc analysis, reductions in total lesion length (TLL) and average lesion length (ALL), which were measured by quantitative coronary arteriography analysis (QCA), were larger in the group with improved glycemic status (from IGT to normal glucose tolerance, or from DM to IGT/ normal glucose tolerance). Result indicated that reductions in TLL and ALL were associated with reductions in levels of fasting glucose, fasting and postprandial insulin, and HDLcholesterol and statin use, but not with levels of either $\mathrm{HbA}_{1 \mathrm{c}}$ or LDL-cholesterol. Author suggested that a glucose lowering strategy, regardless of which type, can reduce progression of coronary artery plaques in patients with early-stage DM or postprandial hyperglycemia.

It remains unclear whether interventions to lower glucose in patients with CVD can reduce cardiovascular events and, if so, what the optimal targets, therapeutic strategies, and timing

The opinions expressed in this article are not necessarily those of the editors or of the Japanese Circulation Society.

Received January 17, 2012; accepted January 17, 2012; released online January 28, 2012

Department of Cardio-Diabetes Medicine (M. Shimabukuro), Department of Cardiovascular Medicine (M. Shimabukuro, M. Sata), The University of Tokushima Graduate School of Health Biosciences, Tokushima; and Second Department of Internal Medicine, Endocrinology, Diabetes and Metabolism, Hematology and Rheumatology, University of the Ryukyus Graduate School of Medicine, Okinawa (H.M.), Japan

Mailing address: Michio Shimabukuro, MD, PhD, Department of Cardiovascular Medicine \& Department of Cardio-Diabetes Medicine, The University of Tokushima Graduate School of Health Biosciences, 3-18-15 Kuramoto, Tokushima 770-8503, Japan. E-mail: mshimabukuro-ur@umin.ac.jp

ISSN-1346-9843 doi:10.1253/circj.CJ-12-0062

All rights are reserved to the Japanese Circulation Society. For permissions, please e-mail: cj@j-circ.or.jp 


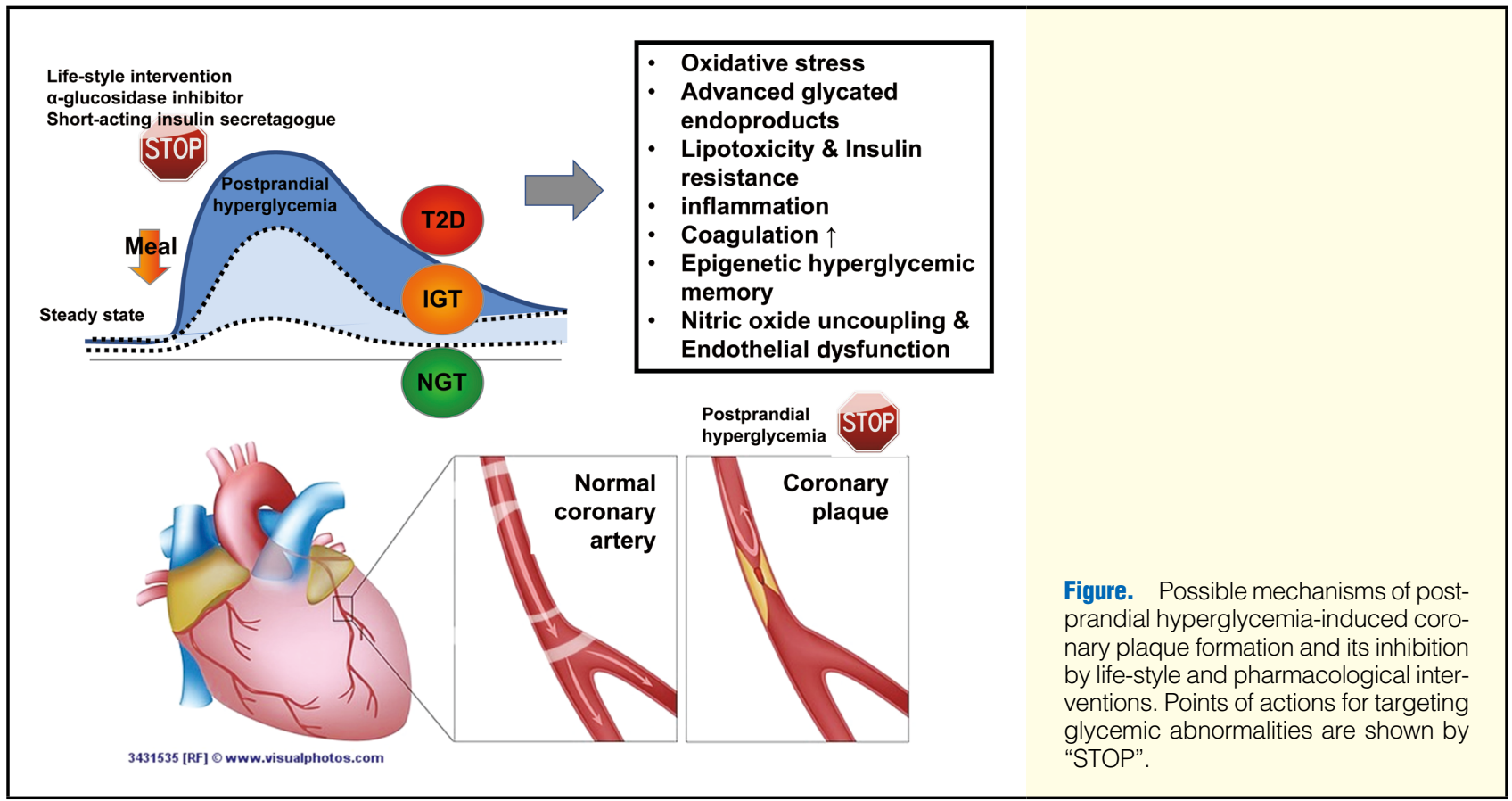

for such interventions should be. Glucose levels after either a glucose challenge or a meal, are more closely associated with cardiovascular risk than are fasting glucose levels, ${ }^{3}$ suggesting that postprandial glycemia may be a distinct therapeutic target. Lowering postprandial glucose levels with the $\alpha$-glucosidase inhibitor, acarbose, has been reported to decrease the risk of MI among persons with IGT. ${ }^{11}$ Short-acting insulin secretagogues are an alternative postprandial glucose-lowering approach. Schramm et al have reported their results of a nationwide registry-based observational analysis of clinical outcomes associated with various insulin secretagogues. ${ }^{12}$ Sulfonylureals such as glimepiride, glibenclamide, glipizide and tolbutamide were associated with increased risk of CVD outcomes as compared with metformin, which is proven to reduce CVD risk. ${ }^{5,6}$ On the other hand, repaglinide, another short-acting insulin secretagogue, was comparable to in metformin for CVD outcomes. ${ }^{12}$ Because a large clinical trial with nateglinide failed to find reduced CVD outcomes, ${ }^{13}$ the strategy using short-acting insulin secretagogue remains to be elucidated. The current trial of 2 drugs, voglibose and nateglinide, may support the anti-atherosclerotic effect of pharmacological interventions targeting postprandial glucose and the mechanisms linking abnormal glucose metabolism to CVD. ${ }^{10}$

Possible mechanisms by which lifestyle interventions or pharmacological interventions with voglibose and nateglinide reduce atheroma progression are as follows. First, reduction in postprandial glucose may reduce oxidative stress. Numerous studies support the hypothesis of a causal relationship between postprandial hyperglycemia and oxidative stress. ${ }^{9}$ Oxidative stress has been implicated as the underlying cause of both the macrovascular and microvascular complications associated with type $2 \mathrm{DM}$. Second, endothelial dysfunction may be corrected by reducing postprandial hyperglycemia. There is indirect evidence of benefit to postprandial endothelial function ${ }^{7,8}$ by administration of an $\alpha$-glucosidase inhibitor and a shortacting insulin secretagogue.,914 Third, lifestyle or pharmacological interventions targeting postprandial hyperglycemia can be associated with weight loss and thus may reduce concomi- tant insulin resistance (IR). ${ }^{14}$ There is solid evidence supporting the notion that excess abdominal fat or ectopic fat disposition is predictive of IR and the presence of related metabolic abnormalities, including IGT and postprandial hyperglycemia. ${ }^{14}$ In the current study, all groups of patients either with lifestyle or voglibose/nateglinide interventions showed reductions in body mass index and HOMA-IR, an index of IR, concomitant with a rise in adiponectin levels. It is suggested that IR through lipotoxicity mechanisms is removed by reducing abdominal fat or ectopic fat disposition. For individuals with type $2 \mathrm{DM}$, moderate weight loss (5\% of body weight) is associated with decreased IR, improved measures of glycemia and lipemia, and reduced blood pressure. ${ }^{14}$ Look AHEAD (Action for Health in Diabetes) is a large clinical trial designed to determine whether long-term weight loss will improve glycemia and prevent cardiovascular events in subjects with type 2 DM. Intensive lifestyle intervention in that trial shows an average $8.6 \%$ weight loss at 1 -year and a reduction in several CVD risk factors, with benefits sustained at 4 years. ${ }^{15}$ This may support the notion that long-term weight loss, either with life-style or pharmacological interventions, is associated with improvement in CVD outcomes.

In summary, the global epidemic of type $2 \mathrm{DM}$ has prompted a large number of clinical trials aimed at reducing its incidence. Interventions for the underlying lifestyle behaviors (ie, overeating and sedentary lifestyle) that result in obesity, a major cause of the epidemic, have a major and consistent effect in reducing the cumulative incidence of IGT and DM. Moreover, lifestyle and pharmacological interventions targeting glycemic abnormalities may reduce cardiovascular risk factors and eliminate plaque progression in patients with IGT or early-stage DM. Because lack of power with the study may not differentiate the glucose-lowering interventions, the concept for treating postprandial hyperglycemia has yet to be demonstrated in an appropriately powered randomized clinical trial.

\section{References}

1. Emerging Risk Factors Collaboration, Sarwar N, Gao P, Seshasai SR, 
Gobin R, Kaptoge S, et al. Diabetes mellitus, fasting blood glucose concentration, and risk of vascular disease: A collaborative metaanalysis of 102 prospective studies. Lancet 2010; 375: 2215-2222.

2. Coutinho M, Gerstein HC, Wang Y, Yusuf S. The relationship between glucose and incident cardiovascular events: A meta-regression analysis of published data from 20 studies of 95,783 individuals followed for 12.4 years. Diabetes Care 1999; 22: 233-240.

3. DECODE Study Group. Glucose tolerance and cardiovascular mortality: Comparison of fasting and 2-hour diagnostic criteria. Arch Intern Med 2001; 161: 397-405.

4. Hemmingsen B, Lund SS, Gluud C, Vaag A, Almdal T, Hemmingsen $\mathrm{C}$, et al. Intensive glycaemic control for patients with type 2 diabetes: Systematic review with meta-analysis and trial sequential analysis of randomised clinical trials. BMJ 2011; 343: d6898.

5. Stratton IM, Adler AI, Neil HA, Matthews DR, Manley SE, Cull CA, et al. Association of glycaemia with macrovascular and microvascular complications of type 2 diabetes (UKPDS 35): Prospective observational study. BMJ 2000; 321: 405-412.

6. Holman RR, Paul SK, BethelMA, Matthews DR, Neil HA. 10-year follow-up of intensive glucose control in type 2 diabetes. $N$ Engl $J$ Med 2008; 359: 1577-1589.

7. Skyler JS, Bergenstal R, Bonow RO, Buse J, Deedwania P, Gale EA, et al; American Diabetes Association; American College of Cardiology Foundation; American Heart Association. Intensive glycemic control and the prevention of cardiovascular events: Implications of the ACCORD, ADVANCE, and VA diabetes trials: A position statement of the American Diabetes Association and a scientific statement of the American College of Cardiology Foundation and the American Heart Association. Diabetes Care 2009; 32: 187-192.

8. Nathan DM, Buse JB, Davidson MB, Heine RJ, Holman RR, Sherwin $\mathrm{R}$, et al. Management of hyperglycemia in type 2 diabetes: A consen- sus algorithm for the initiation and adjustment of therapy-A consensus statement from the American Diabetes Association and the European Association for the Study of Diabetes. Diabetes Care 2006; 29: $1963-1972$.

9. Ceriello A, Colagiuri S, Gerich J, Tuomilehto J; Guideline Development Group. Guideline for management of postmeal glucose. Nutr Metab Cardiovasc Dis 2008; 18: S17-S33.

10. Kataoka Y, Yasuda S, Miyamoto Y, Sase K, Kosuge M, Kimura K, et al on behalf of the DIANA study investigators. Effects of voglibose and nateglinide on glycemic status and coronary atherosclerosis in early-stage diabetic patients. Circ J 2012; 76: 712-720.

11. Chiasson JL, Josse RG, Gomis R, Hanefeld M, Karasik A, Laakso M. Acarbose treatment and the risk of cardiovascular disease and hypertension in patients with impaired glucose tolerance: The STOP NIDDM trial. JAMA 2003; 290: 486-494.

12. Schramm TK, Gislason GH, Vaag A, Rasmussen JN, Folke F, Hansen ML, et al. Mortality and cardiovascular risk associated with different insulin secretagogues compared with metformin in type 2 diabetes, with or without a previous myocardial infarction: A nationwide study. Eur Heart J 2011; 32: 1900-1908.

13. NAVIGATOR Study Group, Holman RR, Haffner SM, McMurray JJ, Bethel MA, Holzhauer B, et al. Effect of nateglinide on the incidence of diabetes and cardiovascular events. N Engl J Med 2010; 362: $1463-1476$.

14. Shimabukuro M. Cardiac adiposity and global cardiometabolic risk: New concept and clinical implication. Circ J 2009; 73: 27-34.

15. Wing RR, Look AHEAD Research Group. Long-term effects of a lifestyle intervention on weight and cardiovascular risk factors in individuals with type 2 diabetes mellitus: Four-year results of the Look AHEAD trial. Arch Intern Med 2010; 170: 1566-1575. 